\title{
Food consumption and coping strategies of urban-households in Nigeria during the COVID- 19 pandemic lockdown
}

Gideon O. Iheme ${ }^{1}$, Alli O. Jagun ${ }^{2}$, Ifeoma M. Egechizuorom ${ }^{3}$, Obinna C. Ogbonna ${ }^{4}$, Linda O. Edafioghor ${ }^{5}$, Folasade A. Adeleke ${ }^{6}$, Nwabumma C. Asouzu ${ }^{7}$, Abdulafeez S. Mebude ${ }^{8}$, Hannah C. Enuka $^{9}$, Oluwadamilare E. Kupoluyi ${ }^{10}$, Cynthia C. Onyekwere ${ }^{11}$, Uchechi P. Okwu ${ }^{12}$ Linda E. Olah $^{13}$

${ }^{1}$ Department of Human Nutrition \& Dietetics Michael Okpara University of Agriculture, Umudike, Nigeria

${ }^{2}$ Department of Nutrition \& Dietetics, University of Abuja Teaching Hospital, Gwagwalada, Nigeria

${ }^{3}$ Department of Nutrition \& Dietetics, Federal Medical Centre Umuahia, Nigeria

${ }^{4}$ Department of Dietetics, Obafemi Awolowo University Teaching Hospital, Ile-Ife, Nigeria

${ }^{5}$ Department of Nutrition \& Dietetics, Federal Medical Centre Asaba, Nigeria

${ }^{6}$ Department of Nutrition \& Dietetics, Federal Medical Centre Yola, Nigeria

${ }^{7}$ Department of Nutrition \& Dietetics, Alex Ekwueme Federal University Teaching Hospital Abakaliki, Nigeria

${ }^{8}$ Department of Nutrition \& Dietetics, Ahmadu Bello University Teaching Hospital Zaria, Nigeria

${ }^{9}$ Department of Nutrition \& Dietetics, University of Nigeria Teaching Hospital Ituku Ozalla, Nigeria

10 Department of Nutrition \& Dietetics, Federal Medical Centre, Abeokuta, Nigeria

${ }^{11}$ Department of Nutrition \& Dietetics, Lagos University Teaching Hospital Idi-Araba, Nigeria

12 Department of Nutrition \& Dietetics, University of Benin Teaching Hospital Benin, Nigeria

${ }^{13}$ Department of Dietetics, Jos University Teaching Hospital, Jos Nigeria

Corresponding author: Gideon O. Iheme, ihemegideon@gmail.com, +2347062691795

Acknowledgements: The authors wish to thank all the respondents for their involvement in this

study, especially those who forwarded the survey link to their eligible contacts.

Financial Support: Not applicable

Conflicts of Interest: None

Authorship: G.O.I, A.O.J, I.M.E, O.C.O, L.O.E, F.A.A formulated the research concept and design. All authors except G.O.I and O.C.O were involved in data collection. G.O.I, A.S.M, H.C.E and N.C.A. conducted statistical analyses. G.O.I, O.C.O, O.E.K, C.C.O, U.P.O and L.E.O. drafted the manuscript. The final version submitted for publication was read and approved by all authors 


\section{Abstract}

Background and Objective: The COVID-19 has prompted many countries to adopt temporary "lockdown" as an approach to curtail viral spread. This study investigated the food consumption and coping strategies of urban-households in Nigeria during COVID-19 pandemic lockdown.

Methods: This cross-sectional, web-based study employed a snowball sampling technique to recruit 477 household heads/spouses living in cities/towns of six Nigerian states by encouraging those sent the survey questionnaire link to share with their eligible contacts. Logistic regression was used to reveal the socio-economic determinants of households' food consumption and coping strategies, as reported on self-administered questionnaires. Respondents were asked to retrospectively indicate how lockdown affected their food consumption.

Results: More than half (55.7\%) of respondents and 50.8\% of their spouses reported a decline in their earning capacity. A high (>4days/week) mean consumption frequency of six food groups was reported. Consuming less expensive (mean, $2.64 \pm$ SD 2.44 days/week) or less preferred foods (1.93 \pm 2.04 days/week), and meal rationing (limit portions at meal time $-1.50 \pm 2.11$ days/week, reduce meal number- $1.4 \pm 2.19$ days/week, limit adults intake- $1.28 \pm 2.18$ days/week) were the most common coping strategies adopted by the households.. The likelihood of adopting coping strategies was significantly higher amongst households with income decline, the less educated and self-employed categories.

Conclusion: In this study, a high frequency of diverse food consumption and mild adoption of food related coping strategies was generally observed, however the impact of the lockdown on food coping strategies was significantly felt by some groups. Efforts to target social assistance programs to these disadvantaged groups should be promoted, as it will strengthen their resilience to cope with food crisis.

Keywords: COVID-19 lockdown, coping strategies, consumption frequency, urban households, Nigeria 


\section{Introduction}

After the outbreaks of SARS in China in 2002, Ebola in West Africa and MERS in 2015, the ending of 2019 was marked by a novel coronavirus disease (COVID-19) outbreak in WUHAN China. $^{(1)}$ COVID-19 is a pandemic caused by a novel human coronavirus (SARS-COV-2) previously known as 2019-nCov. ${ }^{(1,2)}$ As at $1^{\text {st }}$ September 2020, over 25 million cases and 850 thousand deaths have been reported globally. ${ }^{(3)}$ The African region is so far the least affected continent with 1,257,315 cases and 29,862 deaths ${ }^{(3)}$, but the numbers are increasing. ${ }^{(1)}$ In Africa, Nigeria has the fourth highest burden of confirmed cases $(54,008)$ and deaths $(1,013){ }^{(3)}$

Due to the high rate of COVID-19 spread and the absence of a vaccine for its treatment/prevention, Nigeria adopted "lockdown" as an approach to reverse epidemic growth, reducing case numbers to low levels. ${ }^{(4)}$ The lockdown strategy in Nigeria entailed social distancing the entire population through restriction of social gatherings, closing educational institutions, halting all non-essential economic activities, and a ban on domestic (inter-state) and international travel. ${ }^{(5,6)}$

In a bid to cushion the economic effect of the lockdown, the Nigerian government intervened in several ways, most notably; the monthly conditional cash transfer of 20,000 (\$52) for four months to 3.6 million poor households, regular payment of government workers, food relief disbursement to disadvantaged groups, continuation of school feeding programs and a $¥ 2.3$ trillion (\$6 million) economic stimulus package. ${ }^{(7)}$ Despite these efforts, it remain unknown how these inputs will be felt in a country where an estimated 90 million people live in extreme poverty, ${ }^{(8)}$ about a quarter (25.5\%) of whom are severely food insecure ${ }^{(9)}$ and over $80 \%$ of the working population are engaged in informal sectors. ${ }^{(10)}$

This COVID-19 induced lockdown is directly affecting food systems through impacts on food supply and demand, and indirectly through decreases in purchasing power, the capacity to produce and distribute food, and the intensification of care tasks, all of which will strongly affect Nigerian households' capacity to meet the nutritional needs of its members. ${ }^{(11)}$

Our study aimed to investigate the food consumption and coping strategies of urban-households in Nigeria during the COVID-19 lockdown using coping strategy index and food consumption frequency/diversity, well documented indicators for assessing households’ food security. (12-14) 


\section{Methods}

Study design and population This cross-sectional survey used an anonymous online questionnaire to collect data from 477 household heads or their spouses living in cities/towns of Lagos, Abuja, Abia, Delta, Oyo, Ogun and Adamawa States.

Sampling technique A non-probability snowball sampling technique was employed. The link to the survey questionnaires were shared on social media platforms to eligible (household head or their spouses) respondents. These accessible populations also referred or forwarded the survey to their contacts to ensure the survey was widely distributed as far as possible.

Data collection Data for this study were collected using an online self-administered questionnaire. The survey questionnaires assessed the relevant household socio-economic characteristics, consumption frequency of diverse foods/food groups and food coping strategies. The data collection process took place within the $7-9^{\text {th }}$ week of the lockdown in Nigeria (4th-23rd, May 2020). At this stage, the lockdown, which had commenced in only 3 Nigerian states, had been extended to almost all the states of the federation.

\section{Data Analysis \\ Food Coping Strategy (FCS)}

This is one of the indirect methods for assessing adaptive strategies adopted by a household to mitigate the risk of food insecurity. The coping strategy questions include: (1) Do you rely on less preferred food? (2) Do you rely on less expensive foods? (3) Do you borrow money to buy foodstuff? (4) Do you purchase food on credit? (5) Do you rely on help from a relative? (6) Do you limit portions at mealtimes? (7) Do you limit adult intake? (8) Do you reduce the number of meals? (9) Do you skip the whole day without eating? Details of this survey instrument as described below were adapted from the CARE/WFPfield methods manual. ${ }^{(15)}$

\section{Severity weight}

Weightings were assigned to each FCS adopted by the households. In this method, FCS 1, 2, 6 were ranked as the least severe and assigned a weighted score of 1; FCS 3, 4, 5, 7, 8 were assigned a weighted score of 2, while FCS 9 was ranked and weighted very severe (weighted score of 4). ${ }^{(15)}$

\section{Relative frequency}

After levels of severity were decided, numerical value was assigned to each FCS in terms of its reported relative frequency of use during the previous week. All times (every day) $=7$; Pretty often 
$(3-4 \mathrm{x} /$ week $)=4.5$; Once in a while $(1-2 \mathrm{x} /$ week $)=1.5$; Hardly at all $(<$ once/week $)=0.5$; never $=$ $0 .^{(15)}$

\section{Calculation of food coping score/index}

The score of each FCS was obtained by multiplying the numeric value by the weighted number. The total FCS score was obtained from the sum of each individual FCS score. ${ }^{(15)}$ A total FCS score less than or equal to 40 indicates low/limited coping strategies were needed, while values above 40 denotes the high coping strategy.

\section{Consumption frequency of diverse food groups}

This indicator is useful for categorizing and tracking households' food security across time by aggregating household level data on the diversity and frequency of food groups consumed over the previous seven days. ${ }^{(16)}$ An average consumption of diversified foods groups less than 4times $(<4 \mathrm{x})$ per week was categorized as low frequency while 4 times/weekly and above was denoted as high consumption frequency.

\section{Statistical Analysis}

Data collected were extracted using Excel version 2016 and imported into IBM SPSS version 22 for analysis. Descriptive statistics (mean, standard deviation, frequency and percentage) were computed for the categorized and continuous variables. Logistic regression was used to identify the socio-economic determinants of household food coping strategies.

\section{Ethics/Informed consent}

This study was conducted according to the guidelines laid down in the Declaration of Helsinki. Informed consent was obtained from the subjects, as they clicked on "proceed" having read the study scope and objectives to affirm to their willingness to undertake the survey.

\section{Results}

\section{Socio-demographic characteristics of respondents}

Table 1 shows the socio-demographic characteristics of respondents. The sample included a preponderance of adults aged 30-39 years (54.3\%), female gender (57.9\%), married (96.0\%) and well educated (tertiary education $-96.9 \%$ ) respondents. There were more respondents working in government institutions (55.3\%) than in private firms $(22.9 \%)$ or individual/personally owned enterprises (17.2\%). 
Table 1: Socio-demographic characteristics of respondents

\begin{tabular}{|c|c|c|}
\hline Variables & Frequency $(N=477)$ & Percentage \\
\hline \multicolumn{3}{|l|}{ Age } \\
\hline $20-29$ & 44 & 9.2 \\
\hline $30-39$ & 259 & 54.3 \\
\hline $40-49$ & 114 & 23.9 \\
\hline $50-59$ & 42 & 8.8 \\
\hline Above 60 & 18 & 3.8 \\
\hline \multicolumn{3}{|l|}{ Sex } \\
\hline Male & 201 & 42.1 \\
\hline Female & 276 & 57.9 \\
\hline \multicolumn{3}{|l|}{ Marital status } \\
\hline Married & 458 & 96.0 \\
\hline Divorced/separated & 5 & 1.0 \\
\hline Widowed & 14 & 2.9 \\
\hline \multicolumn{3}{|l|}{ Educational status } \\
\hline No formal education & 1 & 0.2 \\
\hline Primary education & 3 & 0.6 \\
\hline Secondary education & 11 & 2.3 \\
\hline Tertiary education & 462 & 96.9 \\
\hline \multicolumn{3}{|l|}{ Position in the family } \\
\hline Household head & 214 & 44.9 \\
\hline Spouse/Wife & 263 & 55.1 \\
\hline \multicolumn{3}{|l|}{ Occupation } \\
\hline Unemployed & 22 & 4.6 \\
\hline Self employed & 82 & 17.2 \\
\hline Private establishment & 109 & 22.9 \\
\hline Government establishment & 264 & 55.3 \\
\hline
\end{tabular}




\section{Economic and dietary/health changes experienced during the COVID-19 Pandemic}

Table 2 shows the economic and dietary/health changes associated with the COVID-19 pandemic. More than half of the respondents (55.7\%) and their spouses (50.8\%) reported a decline in their earning capacity. Slightly above a quarter of them (respondents: 27.0\%; spouses: 27.9\%) maintained a stable income during the pandemic. Consumption of local spices (30.8\%), vitamin C rich fruits and vegetables (31.4\%) or combinations (24.4\%) were prioritized by some households for protection against COVID-19. Furthermore, Vitamin C supplements were consumed by a majority (76.6\%) of the households.

Table 2. Economic and dietary/health changes experienced during COVID-19 Pandemic

\begin{tabular}{|c|c|c|}
\hline Variables & Frequency & Percentage \\
\hline \multicolumn{3}{|c|}{$\begin{array}{l}\text { Influence of the pandemic (lockdown) on } \\
\text { income }\end{array}$} \\
\hline Increased greatly & 54 & 11.4 \\
\hline Increased slightly & 28 & 5.9 \\
\hline Unaffected & 128 & 27.0 \\
\hline Decreased slightly & 115 & 24.3 \\
\hline Decreased greatly & 112 & 23.6 \\
\hline Do not earn income again & 40 & 8.4 \\
\hline Total & 477 & 100.0 \\
\hline \multicolumn{3}{|c|}{$\begin{array}{l}\text { Influence of the pandemic (lockdown) on } \\
\text { spouse income }\end{array}$} \\
\hline Increased greatly & 61 & 12.8 \\
\hline Increased slightly & 28 & 5.9 \\
\hline Unaffected & 133 & 27.9 \\
\hline Decreased slightly & 94 & 19.7 \\
\hline Decreased greatly & 101 & 21.2 \\
\hline Do not earn income again & 47 & 9.9 \\
\hline Total & 464 & 97.3 \\
\hline
\end{tabular}




\section{Specific foods consumed for protection against COVID-19}

Local spices (e.g garlic, ginger, onion)

Vitamin C rich fruits (e.g orange, lemon, lime) and vegetables

Local spices and fruits/vegetables

Green tea

Hot water/foods

Others

Total

\section{Specific medications consumed for} protection against COVID-19

Vitamin C supplement

Multi-vitamin/blood capsule

Cellgetivity (immune boosting supplement)

Chloroquine

Routine drugs

Others

Results from Fig 1 reflect an interplay between household dietary diversity and weekly consumption frequency (in days per week). Reports revealed a high mean consumption frequency of foods within the fat and oil categories $(6.10 \pm 3.64$ days/week), followed by meat $(5.95 \pm 3.70$ days/week), staples (5.51 + 1.81 days/week) and vegetables $(5.38 \pm 1.73$ days/week), dairy products $(4.50 \pm 2.26$ days/week $)$, fruits $(4.50 \pm 2.11$ days/week $)$ and legumes/pulses $(3.67 \pm 1.90$ days/week).

Figure 2 shows the mean 7-day recall of household food coping strategies during the lockdown period. Dietary changes to consume less expensive $(2.64 \pm 2.44$ days/week) or less preferred foods $(1.93 \pm 2.04$ days/week), and meal rationing (limit portions at meal time $-1.50 \pm 2.11$ days/week, 
reduce meal number- $1.4 \pm 2.19$ days/week, limit adults intake- $1.28 \pm 2.18$ days/week) were the most common coping strategies adopted by the households.

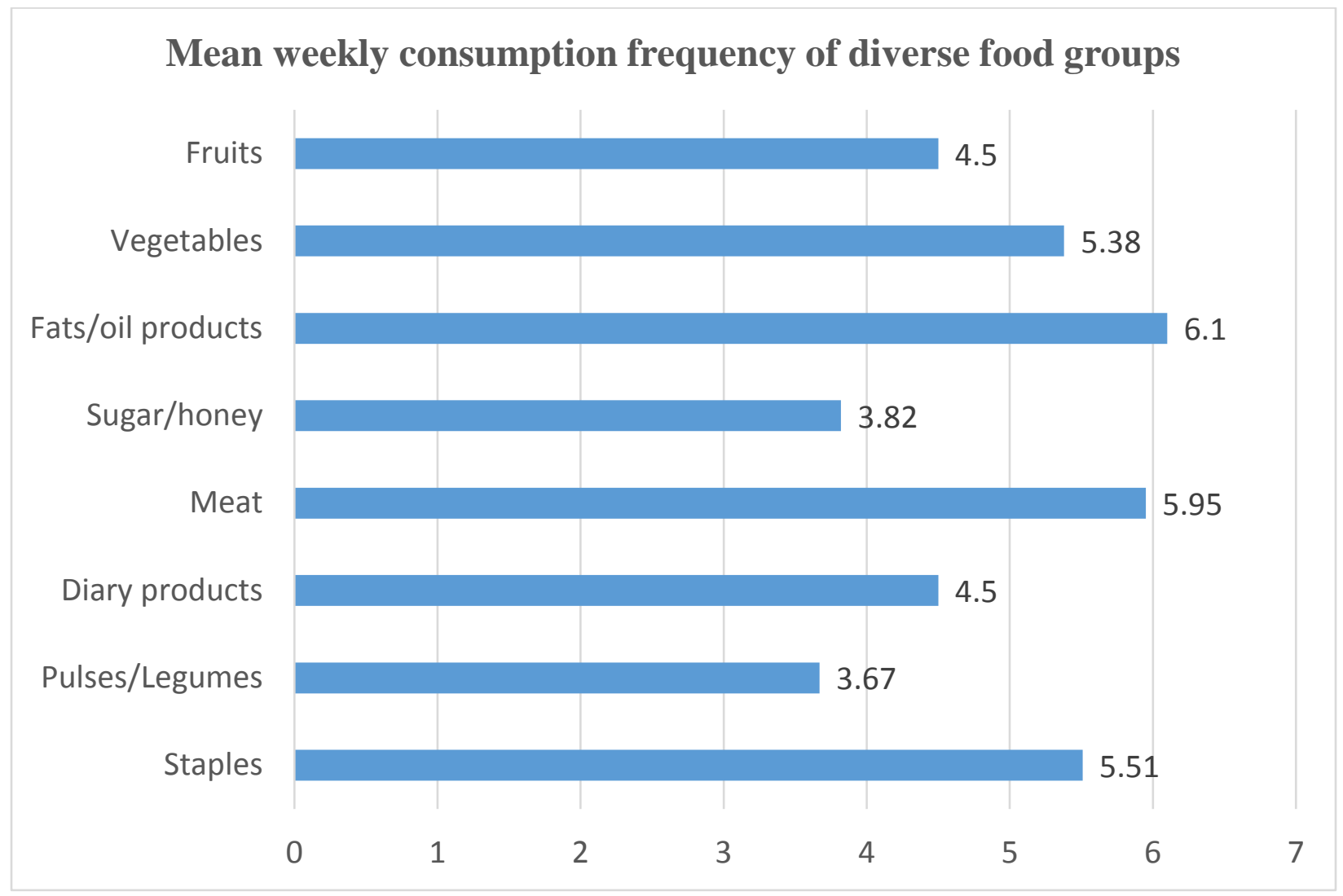

Fig 1. Mean weekly Consumption frequency of foods from various food groups (n=477)

\section{Socio-economic determinants of household food coping strategies}

Results from a logistic regression on the determinants of food coping strategies and food consumption frequency are summarized in Table 3. Results showed that households in which both the heads and spouses experienced a decline in income were 2.92 times more likely to adopt a high coping strategy than those who did not $(\mathrm{OR}=2.92 ; 95 \% \mathrm{CI}=1.10,7.76)$. Respondents with minimal educational background (<secondary education) were 7.89 times at risk of adopting high coping mechanism during the lockdown period than their well-educated counterparts (OR = 7.89; 95\%CI 2.65, 23.41). Self-employed respondents were 6.08 times more likely to adopt high food coping mechanism than their counterparts $(\mathrm{OR}=6.08$; 95\%CI $=3.13,11.80)$. The odds of adopting high coping strategies by government workers were 84\% lower than other forms of occupation $(\mathrm{OR}=0.16 ; 95 \% \mathrm{CI}=0.08,0.50)$. Employees in private firms were $81 \%$ less likely to experience high coping methods than those in the public sector or privately owned enterprise $(\mathrm{OR}=0.16$; 
$95 \%$ CI $0.08,0.50)$. No significant $(\mathrm{p}<0.05)$ association was observed between the socio-economic variables and consumption frequency of diverse food groups.

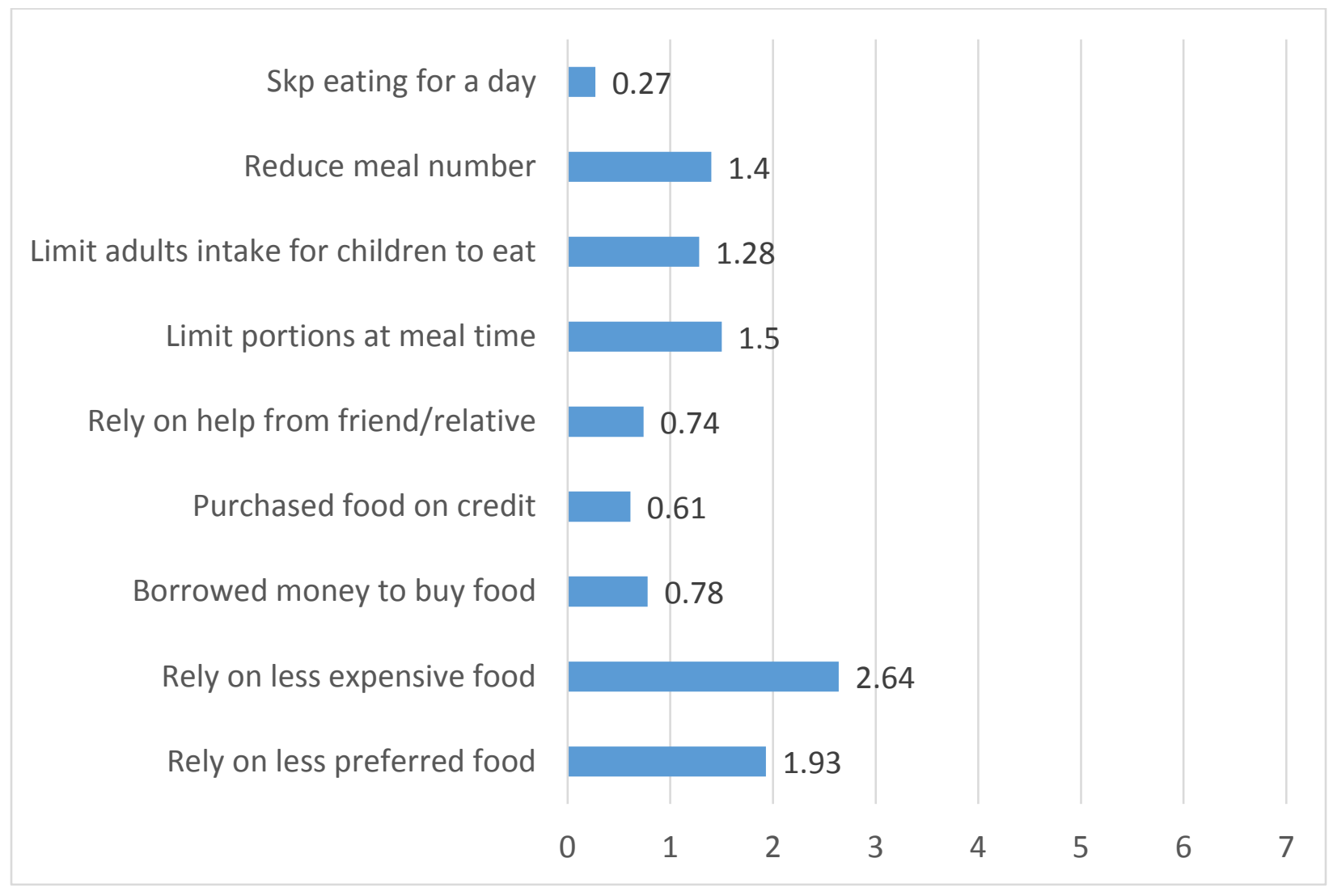

Fig 2. Mean household food coping strategies during the lockdown period $(\mathrm{N}=477)$

\section{Discussion}

COVID-19 has become one of the largest and most economically harmful pandemics in history. ${ }^{(3,}$ 10, 17) This study was designed to assess the food coping strategies and consumption patterns of Nigerian households during the COVID-19 lockdown. The fact that so many Nigerian households have little or no access to or expertise using internet-based applications prevented this internetbased study from achieving a complete demographic profile. The involvement of young married females and well-educated adults in this study is supported by strong evidences that social media utilization in Nigeria is dominated by the young, ${ }^{(18,19)}$ by women, ${ }^{(20)}$ and by the educated. ${ }^{(21)}$ 
The observed income reduction of more than half of the households corroborates with several studies which reported that the COVID-19 lockdown has contributed to a 40-80\% decline in the earning capacity of families in developing countries. ${ }^{(22-25)}$ This illustrates the huge economic shock

Table 3. Socio-economic determinants of household food coping strategies

\begin{tabular}{|c|c|c|c|c|}
\hline & \multicolumn{2}{|c|}{ High food coping strategy } & \multicolumn{2}{|c|}{$\begin{array}{l}\text { Low intake freq. of diverse } \\
\text { foods }\end{array}$} \\
\hline & OR & $95 \% \mathrm{CI}$ & OR & $95 \% \mathrm{CI}$ \\
\hline \multicolumn{5}{|l|}{ HH with income decline } \\
\hline Both spouses & $2.92^{*}$ & $1.10-7.76$ & 1.52 & $0.98-2.39$ \\
\hline At least a spouse & 1.52 & $0.45-5.11$ & 1.35 & $0.83-2.18$ \\
\hline \multicolumn{5}{|l|}{ Marital status } \\
\hline $\begin{array}{l}\text { Divorced/separated } \\
\text { category }\end{array}$ & 2.54 & $0.66-9.79$ & 0.72 & $0.21-2.51$ \\
\hline \multicolumn{5}{|l|}{ Educational status } \\
\hline $\begin{array}{l}\text { Low educational status } \\
\text { ( } \leq \text { secondary) }\end{array}$ & $7.89^{* *}$ & $2.65-23.41$ & 1.98 & $0.66-5.94$ \\
\hline \multicolumn{5}{|l|}{ Occupation } \\
\hline Self employed & $6.08^{* *}$ & $3.13-11.80$ & 1.50 & $0.87-2.60$ \\
\hline $\begin{array}{l}\text { Working in private } \\
\text { establishment }\end{array}$ & $0.19^{* *}$ & $0.08-0.50$ & 1.56 & $0.91-2.67$ \\
\hline Government establishment & $0.16^{* *}$ & $0.08-0.33$ & 0.65 & $0.42-1.02$ \\
\hline
\end{tabular}

AOR $=$ adjusted odds ratio

${ }^{* *} \mathrm{P}=<0.01$

${ }^{*} \mathrm{P}=<0.05$

of unprecedented scale this lockdown has created in households, including those normally not considered to be disadvantaged and the potential to exacerbate food security in Nigeria.

The consumption of natural spices, hydroxychloroquine and multivitamins/or so-called blood capsules as precautions to the spread of the pandemic is an indication that the knowledge and 
perception of preventive behavior amongst Nigerians includes some potential misconceptions. Hassan $^{(26)}$ pointed out that social media platforms and other informal communication channels have been used to spread fear, project fake news concerning the virus, incite panic buying, proffer fake/unverified cures, and undermine medical advice deliberately or ignorantly. Although, a healthy immune system has been advocated as weapon for COVID-19 prevention and nutrition is well recognized as a crucial factor for modulating immune homeostasis, ${ }^{(27,28)}$ consumption of these specific foods/medications has not been proven to be preventive or curative against COVID-19 infection.

The reported high mean consumption frequency ( $\geq 4$.5days/week) of most food groups, particularly the fruit and vegetable groups, is similar to reports on fruit and vegetable consumption of previously reported local studies, ${ }^{(29,30)}$ thus suggesting that consumption frequency of these foods may not have declined as a result of lockdown. This commendable high fruit and vegetable consumption alongside the intake of meat and dairy products could be attributed to widespread but unsubstantiated beliefs about COVID-19 curative or preventive remedies.

The most common dietary coping strategies employed by households in this study were shifts toward consuming less expensive/preferred foods and meal rationing. This is consistent with other reports on coping strategies for household food insecurity from Nigeria, Ghana, South Africa and Ethiopia. $^{(31-34)}$

A decline in household income significantly influenced the adoption of high coping strategy in this study. Several studies have reported that low household income level is significantly associated with food insecurity and household coping strategies. ${ }^{(35,36)}$ Therefore when lockdown reduces incomes for both the primary and supportive household earners, they will be compelled to reduce the cost and thus the quality and/or quantity of foods consumed.

Low educational status was found to be a significant determinant of household coping strategies and this corroborates with findings from previous studies on household food insecurity. ${ }^{(37-39)}$ People with higher education tend to have higher income and accumulate savings to cope with adverse economic disruptions.

This study reports that self-employed respondents were 6 times more likely to resort to household food related coping strategies than those working in private firms or government establishments 
but no relevant studies were found to compare this to. Nevertheless, this highlights the category of workers hit hardest by the lockdown, underscoring that the ongoing social protection scheme (such as the conditional cash transfer and food relief disbursement) is either not adequate in sustaining livelihood or not channeled to the most disadvantaged groups.

\section{Conclusions}

This article identified a high consumption frequency of foods from diverse food groups and the adoption of coping strategies for food insecurity that may not be considered severe in the African context. The lockdown reduced most households' earning capacity, and the less educated, selfemployed and households with both head and spouse losing incomes were the ones most likely to need to utilize dietary coping steps in response to food insecurity. Therefore, the laudable 2.3 trillion stimulus package earmarked by the Nigerian government for economic recovery, particularly the credit facility for affected households and small and medium enterprises, should be increased or better targeted. 


\section{References}

1. World Health Organisation (2020). Coronavirus disease 2019 (COVID-19) Situation Report 90. Geneva: WHO. www.who.int/emergencies/diseases/novel-coronavirus-2019/situation-reports

2.Zhu N, Zhang D, Wang W, et al. (2020) A novel coronavirus from patients with pneumonia in China, 2019. $N$ Engl J Med. 382:727-733.

3.Worldometer (2020). COVID-19 Coronavirus Pandemic. Dover, Delaware: Worldometers.info. www.worldometers.info/coronavirus/

4. Nigeria Centre For Disease Control (NCDC) (2020). COVID-19 guidance for safe mass gatherings in Nigeria. www.covid19.ncdc.gov.ng

5. Radio Nigeria (2020). President Buhari urges caution, not fear over Covid-19. https://www.radionigeria.gov.ng/2020/03/19/president-buhariurges-caution-not-fear-overcovid_19-full-text/

6. Ewodage, R. (2020). COVID-19: How We Plan To Implement Social Distancing In Lagos Markets, Transport System - Sanwo-Olu. https://www.channelstv.com/2020/03/22/covid19-how-we-plan-to-implement-socialdistancing in-Lagos-markets-transport-system

7. Human Right Watch (2020). Nigeria: Protect most vulnerable in COVID-19 response. https://www.hrw.org/news/2020/04/14/nigeria-protect-most-vulnerable-covid-19-response

8. World Bank (2015). World development indicators, depth of food deficit. https://www.data.worldbank.org

9. Food Agriculture Organization Statistics (2016). Statistical pocketbook.

10. International Labour Organisation (2018). Monitor: COVID-19 and the world of work. Third edition.

https://www.ilo.org/wcmsp5/groups/public/dgreports/dcomm/documents/briefingnote/wcms_743 146.pdf

11. FAO (2020). Anticipating the impacts of COVID-19 in humanitarian and food crisis contexts. Rome. https://doi.org/10.4060/ca8464en

12. Ogundari K (2013). Determinants of food-poverty states and the demand for dietary diversity in Nigeria, Fourth International Conference, September 22-25, Hammamet, Tunisia 161302, African Association of Agricultural Economists (AAAE).

13. Samuel FO, Otitoju IO, and Okekunle AP (2020). Household Food Insecurity, Coping Strategies and Child Dietary Diversity (24-59 months) in Ibadan, Nigeria. World Nutrition 11 (1):129-144. https://doi.org/10.26596/wn.2020111129-144 
14. Ahmad AN, Ahmad W, Arman R et al. (2020). Community Perception Survey-COVID-19. The Johanniter International Assistance.

15. CARE/WFP (2003). The Coping Strategies Index: Field Methods Manual. Nairobi: CARE and WFP.

16. International Dietary Data Expansion Project (INDDEX Project) (2018). Data4Diets: Building Blocks for Diet-related Food Security Analysis. Tufts University, Boston, MA. https://inddex.nutrition.tufts.edu/data4diets. Accessed on 23/07/2020

17. International Monetary Fund (2020). World Economic Outlook: The Great Lockdown. https://www.imf.org/en/Publications/WEO/Issues/2020/04/14/weo-april-2020

18. Nnamonu T (2013). Social Media and Youth Development. Int J Adv Dev Stud 7(5):18-22

19. Umekachikelu FC (2013). The Effect of Social Media on Youth Development www.nigeriavillagesquare.com

20. Pew Research Centre Survey (2018). Social Media Use by Gender. http://pewrsr.ch/1KS03ST

21. Amaeshi BO, Ayanwu EU, Oparaku DC (2006). Characteristics of Internet users in Nigeria: The case of Owerri Metropolis, Imo State. Ref Libn 1:8-14.

22. Farzana A, Amrita D, Sanchari R (2020). How has Covid-19 crisis affected the urban poor? Findings from a phone survey. Poverty \& Inequality. https://www.ideasforindia.in/topics/povertyinequality/how-has-covid-19-crisis-affected-the-urban-poor-findings-from-a-phone-survey.html

23. Matthieu T, Céline Z (2020). The economic impact of COVID-19 lockdowns in Sub-saharan Africa; International Growth Center, Policy Brief. www.igc.org/covid-19

24. Thurlow J (2020). COVID-19 lockdowns are imposing substantial economic costs on countries in Africa. International Food Policy Research Institute. https://www.ifpri.org/blog/covid-19lockdowns-are-imposing-substantial-economic-costs-countries-africa

25. Hossain ZR \& Imran M (2020) Livelihood, coping and support during COVID-19 crisis. Power and Participation Research Centre.

https://ec.europa.eu/knowledge4policy/publication/livelihoods-coping-support-during-covid-19crisis_en

26. Hassan I (2020). The other COVID-19 pandemic: Fake news. https://africanarguments.org/2020/03/26/the-other-covid-19-pandemic-fake-news/

27.Bhaskaram P (2001). Immunobiology of mild micronutrient deficiencies. Br J Nutr 85(2):7580 . 
28. Calder PC, Carr AC, Gombart AF, et al. (2020). Optimal nutritional status for a wellfunctioning immune system is an important factor to protect against viral infections. Nutrients 12(4):1181-1187.

29. Olatona FA, Sosanya A1, Sholeye OO et al. (2018) Knowledge of fruits and vegetables, consumption pattern and associated factors among adults in Lagos State, Nigeria. Res J Health Sci 6(2):50-62.

30. Oyedele OO, Adeoye IB, Amao, IO, et al. (2014). Fruit Consumption among Staff of Agricultural Based Institutions. J Biol Agric Healthcare 4(26):161-167.

31. Rebecca AA, Ige AS (2013). Determination of farmers' coping strategies to household food insecurity in Oyo state Nigeria. Am J Soc Mgt Sci 4(1):1-7.

32. Chagomoka T, Unger S, Drescher A, et al. (2016). Food coping strategies in northern Ghana. A socio-spatial analysis along the urban-rural continuum. Agric \& Food Security 5(4):334-342.

33. Ngidi MS, Hendriks SL (2014). Coping with food insecurity in rural South Africa: the Case of Jozini. KZN Med J Soc Sci 5(25):278-289.

34. Tsegaye AT, Tariku A, Worku, AG, et al. (2018). Reducing amount and frequency of meal as a major coping strategy for food insecurity. Arch Public Health 76:56-65.

35. Rashid DA, Langworthy M, Aradhyula S, et al (2006). Livelihood shocks and coping strategies: an empirical study of Bangladesh households. American Agricultural Economics Association Annual Conference, Long Beach, California, July 23-26.

36. Farzana FD, Rahman AS, Sultana S, et al. (2017). Coping strategies related to food insecurity at the household level in Bangladesh. PLoS One 12(4).

37. Ngongi AM (2013). Food insecurity and coping strategies of farm households in Kahama District, Tanzania.

http://suaire.sua.ac.tz:8080/xmlui/bitstream/handle/123456789/581/ANNA\%20MARCO\%20NG ONGI.pdf?sequence $=1$ \&isAllowed $=y$

38. Motbainor A, Worku A, Kumie A (2016). Level and determinants of food insecurity in east and west Gojjam zones of Amhara region, Ethiopia: a community based comparative crosssectional study. BMC Pub Health. 16:1-13.

39. Asesefa KM, Tamiru D, Teshome, MS, et al (2018). Household food insecurity and coping strategies among pensioners in Jimma Town, South West Ethiopia. BMC Pub Health 18:13731381. 